\title{
Co-relation of initial Computed tomography findings with prognosis in head injury cases, mainly based on basal cistern status and mid-line shift parameters
}

\author{
Anuj Kumar Tripathi ${ }^{1}$, Saurabh Pathak ${ }^{2, *}$ \\ ${ }^{1}$ Assistant Professor, ${ }^{2}$ Associate Professor, Dept. of Surgery, ${ }^{1,2}$ Career Institute of Medical Sciences and Hospital, Lucknow, Uttar Pradesh, \\ India
}

*Corresponding Author: Saurabh Pathak

Email: drsaurabhpathak@yahoo.com

\begin{abstract}
Head injury is a major public health problem with higher morbidity and mortality in young people and continues to be one of the most common clinical problems treated by neurosurgeon. In 1973 Hounsfield introduced computerized scanning of head. Invention of CT scan was a major breakthrough in management of head trauma patients.

This technique involved no hazards or discomfort for the patient, and structural disease processes affecting the brain were identified with a clarity exceeding traditional methods. Neuroradiologic practice was transformed overnight and Hounsfield was subsequently awarded the Noble prize for medicine.
\end{abstract}

Keywords: Head injury, Computed tomography (C.T Scan), Health problem.

\section{Introduction}

Head injury is a major public health problem and has already attained an epidemic proportion in India. It has higher morbidity and mortality in young people and continues to be one of the most common clinical problems treated by neurosurgeon. Computerized tomography scan has established itself as a rapid, reliable and non invasive tool to diagnose various head trauma lesions. The lesion or lesions in CT scan if they can definitely be linked with prognosis, may help a lot in management of head injury patients.

In 1974, Jennet B and Teasdale $\mathrm{J}^{2}$ grave a neurological scale for head injury patients which came be known widely as a Glasgow Coma Scale. After GCS score another major breakthrough management of head trauma patients was invention of CT scan (1973). Soon after CT scan began to show promise as a neuroradiological diagnostic test, one of its most use aspect appeared to be the evaluation of patients with head injury because of its rapidity, reliability and non invasiveness.

Backer DP el al ${ }^{3}$ 1977) noted that patients with intracranial mass lesion had a poorer outcome than those with diffuse brain injury and the patient with longer midline shift in mass lesion group had still poorer outcome. They found that abnormal motor response, impaired or absent oculocephalic response and bilateral absence of pupillary light response were all more common in patient with midline shift of $10 \mathrm{~mm}$ or more. Young B et $\mathrm{al}^{4}$ (1981) analyzed relationship between Glasgow coma scale score, midline shift and outcome of patient in their study of 170 patients of head injury. The patient with initial GCS score of 5-7 with midline shift of less than $4.1 \mathrm{~mm}$ on initial CT scan had a significantly higher favorable outcome rate when compared to patient with a large shift.

\section{Material and Method}

This retrospective study is based on 518 head injury cases admitted in apex trauma center of Career Institute of Medical Sciences and Hospital, Lucknow between Feb 2017 to May 2018 and who subsequently underwent computerized tomographic scanning within 24 hours of head injury.

\section{Criteria for Inclusion}

CT scan cranium within 24 hours of injury, No firearm injury, Not associated with other systems involvement like chest injury Abdominal injury, Major fracture. The status of basal cistern (perimesen cephalic cistern), and degree of mid line shift and amount of mass lesion (extradent hematoma, subdural hematoma, intracerebral hematoma, contusion and diffuse cerebral edema were noted.

\section{Observation}

The present study is comprising of retrospective study of 518 cases of head injury admitted in the CIMSH, Lucknow between Feb 2017 to May 2018. Male to Female ratio was 8.1:1 and maximum head injury was seen in 21-30 yr. (37.7\%). The mode of injury in the majority of the cases has been found to be road traffic accident (38.0\%) and fall from height (36.5\%).

\section{Radiological Features}

The patients of head injury were subdivided into six major groups according to their initial CT findings. The frequency of diagnostic categories are shown in Table 1 
Table 1: Incidence of various diagnostic categories

\begin{tabular}{|c|c|c|c|}
\hline Diagnostic category & \multirow{2}{*}{ No of Cases } & \multicolumn{2}{|c|}{ Result } \\
\cline { 3 - 4 } & & Survived (percentage) & Expired (percentage) \\
\hline Extradural hematoma & $81(15.6 \%)$ & $70(86.4)$ & $11(13.6)$ \\
\hline Acute subdural hematoma & $42(8.1 \%)$ & $23(54.8)$ & $19(45.2)$ \\
\hline Intracerebral hematoma & $27(5.2 \%)$ & $17(63)$ & $10(37)$ \\
\hline Contusion & $112(21.6 \%)$ & $80(71.4)$ & $32(28.6)$ \\
\hline Diffuse Cerebral edema & $117(117 \%)$ & $97(82.9)$ & $20(17.1)$ \\
\hline Normal scan & $139(26.9 \%)$ & $133(95.7)$ & $6(4.3)$ \\
\hline Total & 518 & 420 & 98 \\
\hline
\end{tabular}

Abnormal CT was seen in 379 cases (73.2\%) out of 518 cases. Amongst abnormal CT scan group, least mortality was seen in EDH group (13.6\%) while acute SDH group was associated with highest mortality (45.2\%).

In EXTRADURAL HEMATOMA Group Mortality rate was 4.7\%, 7.4\% and 63.6\% in $<50 \mathrm{cc}, 50$ to $100 \mathrm{cc}$ and $>100 \mathrm{cc}$ group respectively. Relation with mid line shif and basal cistern is given in table 2 and 3 respectively.

Table 2: Relation between midline shift and outcome

\begin{tabular}{|c|c|c|c|c|}
\hline Midline shift & $\begin{array}{c}\text { No. of cases } \\
(\mathbf{n . 8 1})\end{array}$ & Survived (\%) & \multicolumn{2}{|c|}{ Expired (\%) } \\
\cline { 3 - 5 } & 11 & $11(100)$ & & - \\
\hline No shift & 15 & $15(100)$ & & - \\
\hline$<2 \mathrm{~mm}$ & 18 & $17(94.4)$ & 1 & $(5.6)$ \\
\hline $2-5 \mathrm{~mm}$ & 30 & $25(83.3)$ & 5 & $(16.7)$ \\
\hline$>5$ to $<10 \mathrm{~mm}$ & 7 & $2(28.6)$ & 5 & $(71.4)$ \\
\hline$\geq 10 \mathrm{~mm}$ & &
\end{tabular}

Table 3: Relation between status of basal cistern and outcome

\begin{tabular}{|c|c|c|c|}
\hline \multirow[t]{2}{*}{ Basal cistern status (Perimesencephalic cistern) } & \multirow{2}{*}{$\begin{array}{c}\text { No. of cases } \\
(n=81)\end{array}$} & \multicolumn{2}{|c|}{ Result } \\
\hline & & Survived (\%) & Expired (\%) \\
\hline Normal & 21 & $21(100)$ & - \\
\hline Effaced & 47 & 44 (93.6) & $3(6.4)$ \\
\hline Obliterated & 13 & $5(38.5)$ & $8(61.5)$ \\
\hline
\end{tabular}

\section{Acute Subdural Hematoma}

In this study there was 42 cases of acute SDH. 19 patients expired out of 42 cases of acute SDH. The mortality rate was $45.2 \%$ in this study. Maximum thickness of acute SDH varied between $3 \mathrm{~mm}$ to $12 \mathrm{~mm}$. Mortality rate was $27.6 \%$ and $84.6 \%$ in $<5 \mathrm{~mm}$ and $>5 \mathrm{~mm}$ thickness group respectively. Relation with mid line shif and basal cistern is given in table 4 and 5 respectively.

Table 4: Relation between midline shift and outcome

\begin{tabular}{|c|c|c|c|}
\hline \multirow{2}{*}{ Midline shift } & No. of cases $(\mathbf{n}=\mathbf{4 2})$ & \multicolumn{2}{|c|}{ Result } \\
\cline { 2 - 4 } & & Survived (\%) & Expired (\%) \\
\hline No shift & - & - & - \\
\hline$<2 \mathrm{~mm}$ & - & - & $2(12.5)$ \\
\hline 2 to 5 & 16 & $14(87.5)$ & $12(60)$ \\
\hline$>5$ to $<10 \mathrm{~mm}$ & 20 & $8(40)$ & $5(83.3)$ \\
\hline$\geq 10 \mathrm{~mm}$ & 6 & $1(16.7)$ & \\
\hline
\end{tabular}

Midline shift was present in all cases of acute SDH. The maximum mortability was seen in $\geq 10 \mathrm{~mm}$ group (83.3\%).

Table 5: Relation between basal cistern status and outcome

\begin{tabular}{|c|c|c|c|}
\hline Basal cistern status & \multirow{2}{*}{ No. of cases (n=42) } & \multicolumn{2}{|c|}{ Result } \\
\cline { 3 - 4 } & & Survived (\%) & Expired (\%) \\
\hline Normal & 4 & $4(100)$ & - \\
\hline Effaced & 20 & $13(65)$ & $7(35)$ \\
\hline Obliterated & 18 & $6(33.3)$ & $12(66.7)$ \\
\hline
\end{tabular}




\section{Intracerebral Hematoma}

The approximate volume of ICH was varied between $15 \mathrm{cc}$ to $130 \mathrm{cc}$. The mortality rate was $20 \%$ in $<50 \mathrm{cc}, 83.3 \%$ in 50 to $100 \mathrm{cc}$ and $100 \%$ mortality rate in $>100 \mathrm{cc}$ group. Relation with mid line shif and basal cistern is given in table 6 and 7 respectively

Table 6: Relation between midline shift and outcome

\begin{tabular}{|c|c|c|c|}
\hline Midline shift (mm) & \multirow{2}{*}{ No. of cases (27) } & \multicolumn{2}{|c|}{ Result } \\
\cline { 3 - 4 } & & Survived (\%) & Expired (\%) \\
\hline No shift & 7 & $6(85.8)$ & $1(14.2)$ \\
\hline$<2$ & 1 & $1(100)$ & - \\
\hline 2 to 5 & 9 & $7(77.8)$ & $2(22.2)$ \\
\hline$>5$ to $<10$ & 6 & $3(50)$ & $3(50)$ \\
\hline 10 & 4 & - & $4(100)$ \\
\hline
\end{tabular}

Table 7:Relation between basal cistern status and outcome

\begin{tabular}{|c|c|c|c|}
\hline Basal cistern status & \multirow{2}{*}{ No. of cases (n=27) } & \multicolumn{2}{|c|}{ Result } \\
\cline { 3 - 4 } & & Survived (\%) & Expired (\%) \\
\hline Normal & 8 & $7(87.5 \%)$ & $1(12.5 \%)$ \\
\hline Effaced & 11 & $8(72.7)$ & $3(27.3 \%)$ \\
\hline Obliterated & 8 & $2(25 \%)$ & $6(75 \%)$ \\
\hline
\end{tabular}

It was observed that greater the compression over basal cistern grater was the risk of death.

\section{Contusion}

In this study, 112 cases of contusion were present. Mortality rate was $28.6 \%$ (32 cases).

Table 8: Relation between number of contusion and outcome

\begin{tabular}{|c|c|c|c|}
\hline Number of contusion & No. of cases (n=112) & \multicolumn{1}{|l|}{ Result } \\
\cline { 3 - 4 } & & Survived (\%) & Expired (\%) \\
\hline Unilateral & 53 & $39(73.6)$ & $14(26.4)$ \\
Single & 25 & $17(68)$ & $8(32)$ \\
Multiple & & & \\
\hline Bilateral & 34 & $24(70.6)$ & $10(29.4)$ \\
\hline
\end{tabular}

Table 9: Relation between midline shift and outcome

\begin{tabular}{|c|c|c|c|}
\hline $\begin{array}{c}\text { Midline shift } \\
\text { (MM) }\end{array}$ & No. of cases (n.112) & \multicolumn{2}{|c|}{ Result } \\
\cline { 2 - 4 } & & Survived (\%) & Expired (\%) \\
\hline No shift & 36 & $34(94.4)$ & $2(5.6)$ \\
\hline$<2$ & 14 & $12(85.7)$ & $2(14.3)$ \\
\hline 2 to 5 & 32 & $27(84.3)$ & $5(15.7)$ \\
\hline$>5$ to $<10$ & 24 & $6(25)$ & $18(75.0)$ \\
\hline$\geq 10$ & 6 & $1(16.7)$ & $5(83.3)$ \\
\hline
\end{tabular}

Mortality rate was maximum in $>5$ to $<10 \mathrm{~mm}(75 \%)$ and $>10 \mathrm{~mm}$ group.

Table 10: Relation between basal cistern status and outcome

\begin{tabular}{|c|c|c|c|}
\hline Basal cistern status & No of cases (n=112) & \multicolumn{2}{|c|}{ Result } \\
\cline { 3 - 4 } & & Survived (\%) & Expired (\%) \\
\hline Normal & 64 & $62(96.9)$ & $2(3.1)$ \\
\hline Effaced & 31 & $15(48.4)$ & $16(51.6)$ \\
\hline Obliterated & 17 & $3(17.7)$ & $14(82.3)$ \\
\hline
\end{tabular}

\section{Diffuse Cerebral Edema}

There were 117 cases of cerebral edema out of 518 cases of head injury. The mortality rate in this group was $17.1 \%$ (20 cases). 


\section{Midline Shift}

Midline shift was present in 208 cases out of 518 cases of head injury.in no midline shift group mortality rate was $1.8 \%$.mortality was $6.7 \%$ in $<2 \mathrm{~mm}$ group, $16 \%$ in 2 to $5 \mathrm{~mm}$ group, $45 \%$ in $>5<10 \mathrm{~mm}$ group and $82.6 \%$ in $>10 \mathrm{~mm}$ group

Table 11.comparison with other studies

\begin{tabular}{|c|c|c|}
\hline Author & midline shift & death/poor response \\
\hline \multirow{2}{*}{ Becker DP et al(3) (1977) } & $<10$ & $15 \%$ \\
\cline { 2 - 3 } & $>10$ & $53 \%$ \\
\hline \multirow{2}{*}{ Young B etal (4) 1981 } & $<4.1$ & $38.6 \%$ \\
\cline { 2 - 3 } & $>4.1$ & $68 \%$ \\
\hline \multirow{2}{*}{ LipperMHetal(10) 1985 } & $<3.8$ & $30 \%$ \\
\cline { 2 - 3 } & $>3.8$ & $63 \%$ \\
\hline AthippanSet al(11) 1993 & Present & $69 \%$ \\
\cline { 2 - 3 } & Abscent & $39 \%$ \\
\hline Present study 2018 & $<5$ & $13.3 \%$ \\
\cline { 2 - 3 } & $>5$ & $53.3 \%$ \\
\hline
\end{tabular}

The present study showed that $>10 \mathrm{~mm}$ and $>5 \mathrm{~mm}$ and $<10 \mathrm{~mm}$ midline shift on initial CT Head were statistically significant $(\mathrm{p}<0.001$ and $\mathrm{p}<.0 .01)$

\section{Basal Cistern}

Normal basal cistern was seen in 156 cases (41.2\%) out of 379 abnormal CT Scan. Mortality rate was $2.6 \%, 22.8 \%$ and $73 \%$ in normal, effaced and obliterated group respectively.

Table 12: comparison of mortality/poor response in other series

\begin{tabular}{|l|c|c|}
\hline \multicolumn{1}{|c|}{ Author } & status of basal cistern & death/poor response (\%) \\
\hline Esperson (5) JOetal(1982) & Obliterated & 66 \\
\hline \multirow{3}{*}{ Dongen KJVet al (12)(1983) } & Obliterated & 93 \\
\cline { 2 - 3 } & Effaced & 38 \\
\cline { 2 - 3 } & Normal & 35 \\
\hline \multirow{3}{*}{ Toutant SM etal(7)(1984) } & Obliterated & 77 \\
\cline { 2 - 3 } & Effaced & 39 \\
\cline { 2 - 3 } & Normal & 22 \\
\cline { 2 - 3 } & Obliterated & 76 \\
\hline \multirow{2}{*}{ S Ratanaalest et al (13)(2002) } & Normal & 27 \\
\cline { 2 - 3 } & Obliterated & 53.6 \\
\cline { 2 - 3 } & Effaced & 21.4 \\
\hline Long LS and Jiang JY(14)(2003) & Normal & 3.9 \\
\hline Present study & Obliterated & 62.9 \\
\hline & Obliterated & 73 \\
\hline & Effaced & 22.8 \\
\hline
\end{tabular}

\section{Discussion}

In this study group we mainly focused on midline shift and basal cistern status within 24 hours CT Head on outcome in head injury cases.

This study showed that obliterated basal cistern was statistically significant $(p<0.001)$ for mortality outcome in comparison to their other counterparts.

\section{Conclusion}

Midline shift and Basal cister status are independent prognostic factor in head injury cases in initial CT Head. Presence of associated lesion (EDH, SDH, ICH, Contusion, Diffuse edema) increases the mortality and morbidity.
Conflict of Interest: None.

\section{References}

1. HounsfieldGN. Computerized transverse axial scanning (tomography) part 1.description of system. Br J Radiol 1973;46:1016-1022

2. Jennett B, Teasdale, Braakman R. Predicting outcomein individual patients after severe head injury. Lancet 1976;1:1031-1034

3. Becker DP, Miller JD. The outcome from severe head injury with early diagnosis and intensive management. $J$ Neurosurg 1977;47:491-5025.

4. Young B, Rapp RP, Norton JA. Early prediction of outcome in head injured patients. J Neurosurg 1981;54:300-303

5. Espersen JO, Peterson of. Computerized tomography (CT) in patients with head injuries. Assessment of outcomebased upon 
initial clinical findings and initial CT scans. Acta Neurochirurgica 1982;655(1-2):81-91

6. Gozzoli L, Cecchini A, RognoneF, Dionigi R, Geraci P.Prognostic value of CT in head injury coma. Ital J Neurol Sci $1983 ; 4(2): 185-190$

7. Tooutamt MS, Klambar MR, Marshal LF. Abscent or compressedbasal cisterns on first CT scan, ominous predictionof outcome in severe head injury. $J$ Neurosurg 1984:6;691-694

8. Lawrwnce F, Marshal MD, Sharon Bowers Maeshall BSN, Melville R, Klauber MD. A new classification of head injury based on computerized tomography. J Neurosurg 1991;75:514-520

9. Valadka AB,Gopinath SP, Robertson CS.midline shiftafter severe head injury, pathophysiological implication. J Trauma 2000;49(1):1-8

10. Lipper MH, KishorePRS, Enas GG. Computed tomography in the prediction of outcomein head injury.AJR1985;144:483-486
11. AthippanS, MuthukumarN, SrinivasanUS. influence of babal cisterns, midline shift and pathology on outcome in head injury. Ann Acad Med Singapore 1993:22(3):452-455

12. Dongan KJV, Braakman R, Gelpke GJ. The prognostic value of computerized tomography in comatose head injured patients, J Neurosurg 1983;59:951-957

13. Ratanalert S, Chompikul J, Hirunpat Sand Pheunpathom N. progression of severe head injury, an experiencein Thailiand. Br J Neurosurg 2002;16(5):487-493

14. Long LS, JIANG jy.the retrospective study of the relationship between perimesencephalic cistern of CT scanning and the outcome of the patients with acute craniocerebral injury. Chil J Traumatol 2003;6(4):226-228.

How to cite this article: Tripathi AK, Pathak S, Co-relation of initial Computed tomography findings with prognosis in head injury cases, mainly based on basal cistern status and mid-line shift parameters. Indian J Anat Surg Head Neck Brain 2018;5(1):21-25. 